\title{
An Ecology for the Re-Enchantment of Life
}

\author{
Carl Hayden Smith \\ Director \\ Ravensbourne University London \\ Greenwich, London, UK \\ c.smith@rave.ac.uk
}

\begin{abstract}
60 years ago, Aldous Huxley stated that "Technology was made for men and not men for technology' but unfortunately, the development of recent social and scientific history has created a world in which man seems to be made for technology rather than the other way around. We have to start thinking about this problem very seriously to see how we can re-establish control over our own inventions." Our current relationship with technology is destroying our cognitive sovereignty. Huxley's Dystopian novel Brave New World seems more applicable and relevant now than ever before. Today, technology is making it possible to enslave us en masse, whilst we perceive ourselves to be free. We are now suffering from such a poverty of vision, in every sense, as we are endlessly distracted by technologies that effectively 'turn off' our depth perception, pattern recognition and long form, critical thinking.
\end{abstract}

Mixed reality. Visual media. Depth perception. Pattern recognition.

\section{LOSS OF AWARENESS}

How have we become blind to the widespread effects of technology on our humanity? What is the cause of this loss of awareness? It is important to understand that not all of these problems are caused by our relationship with technology but also with the limits of our own perception.

For instance:

1) We never see ourselves as we actually are because when we look into a mirror our reflection is reversed front to back, creating a distortion. Even when we use a 'true mirror' device to undo this distortion the result looks unreal. Furthermore, in shop changing rooms (where our buying decisions are made) our perception is often intentionally manipulated by tilting the mirrors to make us look skinnier than we actually are (Carreres 2016).

2) Secondly, we don't hear ourselves as others hear us because of our own physiology. The perception of our voice does not match the external reality. When we consider the role our voice plays in the formation of our identities then we can understand the implications.
3) Thirdly, neuroscience has taught us that we do not see things as they are, but as we are. This is because our brains are prediction machines that can

only process a fraction of the incoming sensory information, leaving the rest dependent on our previous experiences.

4) Finally, to compound all of this our memory is notoriously partial and unreliable.

These 4 areas point us towards the realisation that we are already living in a form of virtual reality.

\section{LIVING SECOND HAND}

As we spend time mesmerised in front of our screens, we become zombified. How can we understand how we got here in order to try and break ourselves out of this state?

\subsection{Lack of peripheral vision:}

Our use of peripheral vision has been in general decline as we adopt technologies with small screen real estates. Unfortunately, this has far reaching 
implications for our perception, our memories and our cognition.

\subsection{Image construction:}

With the intention of trying to understand how our perceptual limitations are formed I explored how the media we commonly interact with is also limited. For example, a standard mobile phone camera only captures between 40 to 80 degrees of the scenes field of view but in reality, we see 180 degrees. (Harding 2019). So, just like with the mirror example the ways images are constructed does not reflect how we actually see, there is an inherent distortion, which we then have to live through.

\subsection{Social media production:}

Now if we apply these media limitations to social media then it is easy to understand why social media leaves us feeling inadequate. We make the mistake of taking the photoshopped version of reality, for reality itself.

\subsection{Mobile phone screen real estate:}

Now let's look at how social media plugs into the tiny real estates of mobile phones. Mobile devices narrow our focus, reducing our awareness of what is going on around us, leading to a second hand zombified form of living. Selfie face distortion which is enabled through mobile phones (which have become our modern-day mirrors) is also driving a reported $30 \%$ increase in nose jobs and other forms of plastic surgery (Belluz 2018).

\subsection{Optic flow:}

Optic flow is "the ability to discern possibilities for action within the environment" (Wikipedia, 2021). Optic flow is the flow of things either side of you as you walk or ride or run. Our entire history was saturated with this locomotive optic flow but now that is much less common. Instead, what we have is this very static vision that keeps us locked in.

We are living in an increasingly mediated world and as a result, we are becoming dependent on digital systems that create narrow perceptual channels and bottlenecks. This is compounded by fact that the first bottleneck with our limited perceptual bandwidth, is actually us.

In summary of this section, we are locked in multiple times in the form of the following stack:

(i) Initially within our own perception, (ii) Then because of the inaccuracy of our image media,

(iii) Then across the board, of our social media,

(iv) Then into our hardware (mobile/screen based) technologies, and

(v) On top of all of that we are literally locked into our lack of bodily movement, and corresponding optic flow.

\section{ECOLOGY OF PRACTICE}

This paper offers an 'ecology of practises' that aim to help us reclaim our humanity from the machine whilst still retaining and taking advantage of the positive benefits that technology offers.

\subsection{Recognising the physiological side effects of technology}

My first career involved reconstructing ancient buildings around the world, using digital 3D modelling.

This is a digital reconstruction of Rievaulx Abbey in Yorkshire:

\section{Figure 1: Digital 3D reconstruction of Rievaulx Abbey in Yorkshire by Carl Hayden Smith}

I experienced a number of very surprising physiological side effects that made me realise the impact that interacting with media can have on our perception:

1) The first of these effects was that my peripheral vision improved, I became a better driver, as I was able to see interactions happening further down the road.

2) Secondly, I would dream about the structures I had built during the day so I realised I was able to program my dreams in this routine way. 
3) Thirdly, I realised that I had inadvertently generated a number of 'memory palaces' because the intricate 3D structures I had constructed were effectively baked into my subconscious.

Let's try to unpack these three powerful effects to see how transferable these practises potentially are?

\subsection{Exercising your peripheral vision is known to have many positive effects:}

-Calming down your physiology

-Crucial to focus and memory

(Yamamoto \& Philbeck 2013).

Doing a lot of large-scale 3D modelling meant I developed a transferable skill: being able to program my dreams. This led me to explore how much perceptual flexibility can be developed in the dream space. Lucid dreamers report that training is more effective within a lucid dream than in normal reality. This is reportedly because they have to apply the contextual factors in addition to performing the content. (Stumbrys et al. 2016).

To add an extra layer of perceptual flexibility for myself I started practising peripheral vision exercises, inside my dreams. This had the effect of actually increasing what I could 'bring back' from those dreams.

Hypnopompic and hypnogogic states are known as the most insightful liminal states. How can we reliably use these states to re-enchant our lives? (Waters et al 2016).

\subsection{Memory palaces}

Memory palaces were made famous by the Greek Orators who didn't write anything down. Instead they generated a virtual location in their minds eye where they stored remembered information.

This 3D Modelling work provided me spatial literacy as a transferable skill, spatial literacy is a greater ability to organise information into space (within my head but also within the world).

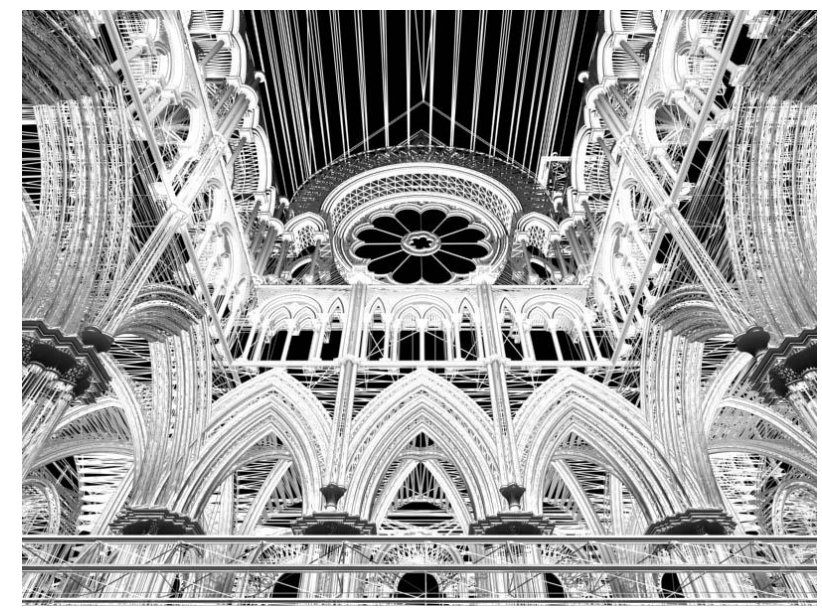

Figure 2: Digital 3D reconstruction of the interior of Rievaulx Abbey, Yorkshire, UK

2) My record collection is another memory palace because i) I know where I purchased each record ii) each record has its own story contained within it and iii) I always need to know where each record is located on the shelf so I know where they are when I want to play them.

3. I have written a diary for 30 years and this is another form of memory palace. Utilising the power of the cross section I can review this day last year and the year before and the year before until I reveal 30 different versions of myself all at different ages. I turn my life itself into architecture in order to lift the insights off the page. Mining my own life experience from the bird's eye view. Insight is gained by taking this higher order perspective on your perspective forming a double consciousness.

4) I even put this paper into a memory palace to see it from every angle and to work out how to structure it.

Remember all of these abilities stemmed from 3D modelling on a 2D screen, so the right kind of computer work can have real world transferable skills.

\subsection{Let's move from the Landscape to Body space}

For the next section of the paper let's move from virtual space back out to physical space with an interactive exercise for your imagination:

- Which types of physical space enchant you?

- Make a note of the places which make you you come alive.

- What landscapes place you into a flow state?

- Notice what environments expand and contract your sense of time. 
- Then try to explore what it is about that space that transforms you?

- Notice, for instance, when you have access to the horizon, how this reinforces your ability to practise your peripheral vision.

- Does this 'looking across as opposed to from' enable new forms of thinking?

- Finally, to regain your agency over your perception, try to enchant the space itself.

- Be as present as you can as you imprint on your space.

- Now try programming your environment with your ideation.

- At the end of this process you may discover that you have turned these enchanted places into memory palaces.

- Next try the same process with your body and see if you can turn your body itself into a memory palace.

- Remember constructing memory palaces is most effective when you know the place inside and out, this is why your own body is an ideal site of investigation.

\subsection{Embodied Cognition}

We learn to read more quickly when we first learn to write by hand and we also remain better able to generate ideas and retain information (Konnikova 2014). In other words, it's not just what we write that matters, but how we write it.

The movements we make with our hands, when we talk, constitute a second language, adding information that's absent from our words. (Paul 2013). Simply put, being embodied aids our ability to think and perceive better.

\subsection{Perceptual Diversity}

The final practise takes us beyond the human altogether in order to practise 'Perceptual Diversity'.

In light of massive loss of biodiversity on the planet how can we learn from other lifeforms before it is too late? Fungi have survived five mass extinctions and are more closely related to us animals than they are to plants - they are our ancestors.

\footnotetext{
"Humans of the past were much more intimate with their ecosystems, and if we are to survive the climate changes before us, we must reacquaint ourselves with the more-than-human life that lives beyond the concrete and computers that define modernity." (Satori 2019)
}

The key question therefore is how can we sense like a mycelium network or sense like a forest? Can we achieve the required synergy through this Perspective or State Shifting otherwise known as Umwelt hacking? Can these other Umwelts be the mechanism we need to have an embodied experience of a nested ecology? Will this in turn, help us to realise that we are not just the predators at the top of the food chain but also entirely dependent on what we are decimating? Will this 'perspective shifting' ultimately help us to reprogram our associations and enable systemic behaviour change?

\subsection{Align Technology with nature}

With the widespread adoption of VR/AR/MR/XR there is a trend towards spatial computing. Mixed reality has serious potential to put us not only back into the body, but back into the world, by reactivating our peripheral vision and our optic flow.

Technology now allows us to investigate the fungal world; opening up the hidden realms that lie beneath us, invisible to the eye. Can we use mixed reality to reveal this intelligence in real time? If we could use the combination of Mixed Reality and $\mathrm{Al} /$ Machine Learning to give us a new form of X-ray vision, this could literally enable us to represent the "internet of fungus" at work under our very feet. As a result, we would immediately see this superior intelligence as it generates mutually beneficial relationships for with all the living systems around it.

Would this instant perspective shifting (enabled through technology) help us to reprogram our associations and enable systemic behaviour change?

Mixed reality has serious potential to put us not only back into the body, but back into the world, by re-activating our peripheral vision and our optic flow. However, Mixed Reality also has the power to degrade reality much like pornography has the potential to degrade the imagination. Once you have seen it you cannot unsee or necessarily live without it.

We must never replace the imagination with computer animation because we can only ever ask the questions that we have the imagination for. As a result, working with the imagination in combination with technology is crucial. Combining the best affordances of the digital with the best affordances of the analogue will enable us to use the virtual to create the actual.

\section{CONCLUSION}

I have attempted to outline an ecology of practice for the re-enchantment of life. These initial practises are really intended to encourage you to make your own. By generating an ecology, we build in resilience and gain the potential to expand our consciousness literacy. 
In summary, our example ecology involves the following guidelines:

1. Create interventions that require the navigation of unfamiliar territory.

2. Adapt to alternative points of view in order to expand our perceptual abilities.

3. Increase our perceptual augmentation to expand our capacity to be in the world.

Through building collectively, we can create a real testament to the imagination (instead of being fed by the algorithm). Remember to turn your ecology into a memory palace to enable cross pollination.

Let us reinvigorate and reignite the senses we have lost in order to return us to that childlike sense of wonder. The full dynamic range of our existence depends on it.

\section{REFERENCES}

Belluz, J. (2018) Selfie face distortion is driving people to get nose jobs. Vox.

https://www.vox.com/science-and-

health/2018/3/1/17059566/plastic-surgery-selfie-

distortion (Retrieved 3rd March 2021).

Carreres, A. (2016) Here's How Fitting Room Mirrors Make You Look a Lot Better Than You Do. https://www.vice.com/en/article/nnki38/changingroom-mirrors-weird-body-image-876 (Retrieved 25th Nov 2020).

Harding, G. (2019) Understanding Focal Length On Smartphone Cameras. [Website] URL:

https://thesmartphonephotographer.com/smartphon e-camera-focal-length (Retrieved 2nd January 2021).
Konnikova, M. (2014) Children learn to read more quickly when they first learn to write by hand. URL: https://www.seattletimes.com/nation-world/childrenlearn-to-read-more-quickly-when-they-first-learn-towrite-by-hand/ (Retrieved 2nd January 2021).

Wikipedia (n.d.) Optical flow. http://en.wikipedia.org/wiki/Optical flow Retrieved 12th January 2021).

Paul, A.M. (2013) Hand Gestures Say A Lot About Your Intelligence. URL:

https://www.businessinsider.com.au/handgestures-reveal-complex-thoughts-2013-6 (Retrieved 2nd January 2021).

Satori, D. Myceliate [website]. URL: https://myceliate.com/about (Retrieved 2nd January 2021).

Stumbrys, T., Erlacher, D., Schredl, M. (2016). Effectiveness of motor practice in lucid dreams: a comparison with physical and mental practice. Journal of Sports Sciences. 34, pp. 27-34. https://www.researchgate.net/publication/27464251 0 Effectiveness of motor practice in lucid drea ms a comparison with physical and mental pra ctice

Waters, F., Blom, J. D., Dang-Vu, T. T., Cheyne, A. J., Alderson-Day, B., Woodruff, P., \& Collerton, D. (2016) What Is the Link Between Hallucinations, Dreams, and Hypnagogic-Hypnopompic Experiences? Schizophrenia bulletin, 42(5), pp. 1098-1109. doi: doi.org/10.1093/schbul/sbw076.

Yamamoto, N., Philbeck, J.W. (2013) Peripheral vision benefits spatial learning by guiding eye movements. Mem Cogn 41, pp. 109-121 https://doi.org/10.3758/s13421-012-0240-2 